\title{
Foodborne Viral Infections
}

\author{
Miren Iturriza-Gomara1,2 \\ Sarah J O’Brien2,3
}

$1=$ University of Liverpool Institute of infection and Global Health, Ronald Ross Building, 8 West Derby Street, Liverpool, L69 7BE

$2=$ NIHR Health Protection Research Unit in Gastrointestinal Infections at the University of Liverpool

3 = University of Liverpool Institute of Psychology, Health and Society, The Farr Institute@HeRC

University of Liverpool, 2nd Floor, Block F Waterhouse Buildings, 1-5 Brownlow Street, Liverpool

L69 3GL

Corresponding Author $=$ Sarah J O’Brien

The Farr Institute@HeRC

University of Liverpool

2nd Floor, Block F Waterhouse Buildings

1-5 Brownlow Street

Liverpool

L69 3GL

Tel: +44 1517958301

E-mail: s.j.obrien@liverpool.ac.uk 


\section{Abstract}

\section{Purpose of review}

To provide an update on foodborne viral infections describing illness burden, the main aetiological agents (enteric viruses, hepatitis viruses and emerging and zoonotic viruses), and advances in virus detection in foods.

\section{Recent findings}

Norovirus (NoV) is the most common viral foodborne pathogen globally (125 million cases and 35,000 deaths). The role of the asymptomatic food handlers in contributing to NoV outbreaks is becoming increasingly clear, with up to one quarter of outbreaks attributable to them. Hand washing with soap and water remains the best method for removing NoV from fingers. Risk assessment for transmission of emerging viruses through the food chain should include consideration of all means by which food could post a hazard i.e. not just consumption. New technologies have demonstrated the widespread nature of viral contamination in the food chain but this does not necessarily correlate with the risk of disease. Finally, understanding people's knowledge and behaviour is just as important as understanding virus characteristics and epidemiology when assessing risks of foodborne transmission.

\section{Summary}

The predominant viruses transmitted through food tend to be those for which humans are the natural hosts, so that effective control measures need to prevent exposure of foods to human faeces.

Key Words

Norovirus, hepatitis A virus, foodborne disease, gastroenteritis, risk assessment 


\section{Abbreviations}

DALY: Disability Adjusted Life Years

EEA: Economic European Area

EU: European Union

HAV: Hepatitis A virus

HBGA: Histo Blood Group Antigen

NiV: Nipah virus

NoV: Norovirus

RT-PCR: Reverse Transcription Polymerase Chain Reaction

SARS: Severe Acute Respiratory Syndrome

SAV: Sapovirus

VLP: Virus Like Particle 


\section{Introduction}

In 2015, for the first time, the World Health Organization published a comprehensive assessment of the burden of food-related illness worldwide[1, 2]. This landmark report provided much needed insight into a major global cause of preventable morbidity and mortality. Thirty-one infectious and chemical hazards included in the research contributed around 600 million foodborne illnesses and 420,000 deaths in 2010 , which was the most recent year for which robust data were available. The global burden of foodborne disease was estimated to be 33 million Disability Adjusted Life Years (DALYs) with children aged less than five years of age bearing the brunt. They suffered $40 \%$ of the total estimated burden of foodborne disease despite representing only $9 \%$ of the global population. There were also regional variations in the burden of foodborne disease. The greatest impact was witnessed in Africa, followed by the parts of South-East Asia and parts of the Eastern Mediterranean, demonstrating the toll of foodborne disease on people living in low-income countries.

\section{Enteric foodborne viruses}

Important viruses that have been linked to foodborne transmission are summarised Table 1 . They display a wide range of clinical features.

Foodborne transmission is mainly associated with enteric viruses like norovirus (NoV), which are shed in high concentrations in faeces and vomit and the virus particles can persist in the environment for several days to months [3-5] In 2010, NoV was responsible for approximately 125 million cases and 35,000 deaths worldwide [6].Noroviruses are non-enveloped with a diameter of 30-35 nm and a single stranded (ss) RNA genome of approximately $7.5 \mathrm{~kb}$. The viruses are very diverse and are classified into six genogroups of which only three cause infection in humans. Within these genogroups 30 genotypes have been described to date [7].Noroviruses are highly infectious and exposure does not lead to long-lasting protection or broad crossprotection against different genotypes. It has been suggested that genotype profiles may be useful for food borne attribution of 
norovirus and in recent estimates it was calculated that $14 \%$ of all norovirus outbreaks may be related to the consumption of contaminated food [8].

High risk food vehicles include fresh produce and oysters as well as transmission via symptomatic, infected food handlers. Noroviruses bind to Histo Blood Group Antigens (HBGA), and differences in the expression of HBGAs are important determinants of susceptibility to norovirus infection and disease. Animal noroviruses also use carbohydrates as host cell binding molecules. Although HBGA are unlikely to be the only factors mediating binding and entry of noroviruses to host cells, differences in the binding of carbohydrates between animal and human noroviruses may have a role in the observed host restriction. Norovirus binding to carbohydrates is also linked to the risk of foodborne transmission; noroviruses specifically bind to HBGA-like molecules present in oysters' guts and, more recently, specific binding of norovirus like particles (VLPs) to HBGA-like carbohydrates present in the cell wall of lettuce has been demonstrated [9].

The association between infected, symptomatic food handlers and the risk of cross-contamination to food is a well-established cause of outbreaks. Increasingly, however, asymptomatic infected food handlers are emerging as important sources of foodborne norovirus outbreaks [10].

Norovirus and sapovirus share similar characteristics. They have similar structures, transmission routes and clinical presentations. They are both frequently detected in faecally contaminated waters and shellfish. However, there are few rigorously investigated outbreaks of sapovirus (SAV) linked to foodborne transmission $[11,12]$. One important difference between them is that, unlike NoV, there is no evidence that SAV bind to HBGAs, and no differential patterns of susceptibility to SAV infections have been identified [13]. These differences may also contribute, to some extent, to their limited foodborne transmission.

Similarly there are relatively few foodborne outbreaks linked to rotavirus $[14,15]$ although the virus can be found on, for example, crops [16].The current rollout of rotavirus vaccines is likely to contribute to further reduction in the risk of contamination of foods through reduced infection and 
shedding. There is also limited evidence of foodborne transmission of astrovirus, which, like rotavirus is primarily transmitted person-to-person $[17,18]$.

There is a wide range of other viruses that are shed in faeces and so could, in theory, cause foodborne illness. For example, aichi viruses are frequently found in contaminated waters, and seroprevalence studies have demonstrated high levels of exposure to these viruses globally, although foodborne transmission has been limited primarily to the consumption of shellfish, principally in Asia. The role in human infection and disease of viruses such bocavirus, cardiovirus, cosavirus, klassevirus, picobirnavirus and torovirus is not yet established [19].

\section{Hepatitis viruses}

WHO estimated that in 2010 hepatitis A virus (HAV) caused around 14 million cases and 28,000 deaths globally [6]. During 2013/14 the largest ever documented foodborne HAV outbreak in Europe occurred $[20,21]$. The outbreak affected more than 1,500 patients in 13 European Union (EU)/European Economic Area (EEA) countries and was associated with consumption of several different types of frozen berries. In a retrospective analysis of outbreaks in Europe over a 30-year period (1983 to 2013) consumption of frozen berries was increasingly associated with reported NoV and HAV outbreaks and contamination events, especially after 2003 [22].

Hepatitis E virus is increasingly recognised as a foodborne pathogen, which has been associated consuming processed pork and can also be found in wild game meat and shellfish [23-27].

\section{Emerging and zoonotic viruses}

Several emerging viruses have posed questions about potential foodborne transmission in recent years. These include SARS coronavirus, H1N1influenza and, currently, Zika virus. When assessing potential risks through the food chain it is important to think widely. This means not confining considerations purely to consumption of contaminated food stuffs but also other means by which food could pose a hazard, e.g. through cutaneous transmission by handling meat to occupational 
groups like veterinary surgeons or abattoir workers, or through bodily secretions other than faeces, such as urine, saliva and (breast) milk. Often key data are lacking and the degree of uncertainty around risk assessment is very high. Nevertheless the process of performing a risk assessment points up important data gaps and can help to target rapid research.

There is, as yet, no direct evidence for foodborne transmission of SARS coronavirus or influenza H1N1 through the food. Although there is a theoretical risk from both agents, which have the potential to be found in the food chain, the main risk is considered to be likely to come from direct contact with infected animals [19].

Infective Zika virus particles have been demonstrated to be present in breast milk with high viral loads [28]. Since vertical transmission via breastfeeding for other arboviruses (dengue, West Nile and Yellow Fever) has been suggested previously, there needs to be very close scrutiny of the potential for transmission of Zika infection via this route.

It is thought that zoonotic viruses like simian herpes viruses, simian immunodeficiency virus and simian foamy viruses can enter the food chain through the butchering of wildlife for bush meat [19, 29]. To underline this, the index case in the 2014/15 Ebola epidemic in West Africa was thought to be an 18-month-old child in Guinea who had contracted the disease through eating or handling bush meat [21]. In general, butchering infected animals is considered the most likely high risk activity, since the viruses are possibly inactivated by cooking [19].

Raw date palm sap has been shown to the contaminated food vehicle in two outbreaks of Nipah virus (NiV) infection in Bangladesh [30, 31]. These outbreaks demonstrate that it is insufficient to consider only virus biology and epidemiology. In a very important follow-up study researchers who investigated these outbreaks surveyed the date palm sap consumption habits of rural residents and the factors associated with consuming date palm sap [32]. They showed that survey respondents' knowledge of NiV was low, that they did not understand the risks of NiV, and that they were likely to 
drink sap when it was available [32]. This shows the critical importance of understanding people's knowledge and behaviour when assessing risks of foodborne transmission.

\section{Technological advances in assessing the risk of foodborne transmission}

Detecting enteric viruses in food relies on molecular methods (RT-PCR principally), which offer sensitive, rapid and specific identification of the presence of the pathogen. Various pre-treatments have been optimised for the successful extraction of virus nucleic acid from food commodities, primarily shellfish, soft berry fruits and salad greens (including a standardised method: ISO/TS 15216-1:2013; Horizontal method for determination of hepatitis A virus and norovirus in food using real-time RT-PCR) [33]. Methods for detecting norovirus in composite foods have also been developed, which are important, particularly in circumstances in which food contamination occurs via the food-handler [34]. However, the biggest challenge remains correlating the detection of viral nucleic acid with infectivity. Various methods have been developed to assess NoV capsid integrity through measuring the degradation of nucleic acid following heat treatment or chemical treatment [35-37] or the ability to bind HBGA [38]. However, demonstrating that viral nucleic acid is protected by a capsid, or that HBGA binding persists, do not necessarily correlate with the ability of the virus to establish infection. For example, inactivating methods like ultraviolet treatment, or the presence of molecules such as antibodies that can potentially neutralise infectivity, do not result in exposure of the nucleic acid. Also, HBGA-like molecules present in bacteria may potentially mask binding assays.

Caliciviruses other than noroviruses have also been used as model systems to study the stability of human NoV and the virucidal effects of disinfectants [39-41]. However these viruses might not model the basic properties of human NoV accurately, and are not ideal substitutes. Furthermore, data from a recent systematic results review suggests that, based on comparative RT-qPCR data, human NoV is likely to be more resistant to typical food and environmental control measures when compared with cultivable surrogate viruses [42]. 
Recently a human NoV in vitro cell culture system has been developed using B cells and an in vivo immunocompromised mouse model has been established that supports human norovirus replication [43]. These exciting advances provide, for the first time, the tools that can potentially lead to our understanding of many aspects of human NoV. These include characterising the virus life cycle at the molecular level, developing therapeutic and prophylactic compounds, improving candidate vaccines, assessing the viability and infectivity of viruses found in foods, and helping to assess risks and develop interventions. Despite their significance, neither of these systems is currently developed in a way that allows their widespread use and, at present, low levels of virus replication remain a major challenge.

\section{Understanding the role of the microbiome}

In the last few years, the role of bacterial flora on enteric virus infections has been an increasing focus of research [44, 45]. In fact, the human norovirus B cell culture model is facilitated by commensal bacteria expressing HBGA-like antigens $[43,46]$. From a food safety perspective, binding of HBGA-expressing bacteria may also protect NoV during food processing treatments [47], and therefore developing or implementing NoV control measures may also require careful consideration of the presence and risks posed by the presence of certain bacterial species.

\section{Controlling the spread of foodborne viruses}

Viruses associated with transmission via the food chain tend to be those for which humans are the natural hosts, so that effective control measures need to be aimed at preventing exposure of foods to human faeces (Figure 1). Vaccines against HAV and rotavirus have already been implemented to good effect and there are now several candidate vaccines for NoV although none is yet close to market. Despite the importance of foodborne transmission of NoV, the predominant mode of spread is person-to-person. Should an effective vaccine become available, one of the challenges will be to establish which population groups should be vaccinated to interrupt transmission most effectively. 
Similarly it will be important to understand how broadly reactive any future candidate vaccines might be against different genotypes and emerging variants.

\section{Conclusions}

Foodborne viruses cause considerable morbidity and mortality. Controlling them still means relying on good personal and food hygiene, good agricultural practice, post-harvest controls and effective management of human sewage to prevent onward transmission. Handwashing with soap and water remains superior to using alcohol-based hand disinfectants for removing NoV from fingers [48]. However hand sanitiser formulations supplemented with urea and citric acid may be more effective against non-enveloped viruses, including NoV [49]. When considering the risk posed by food and the food chain on the transmission of emerging viruses, activities and behaviours beyond food consumption need to be assessed.

\section{Key points}

- $\quad$ Norovirus (NoV) is the most common viral foodborne pathogen worldwide.

- $\quad$ Asymptomatic food handlers may contribute to up to a quarter of outbreaks of NoV.

- Handwashing with soap and water remains superior to using alcohol-based hand disinfectants for removing NoV from fingers.

- Assessing risks through the food chain should not be confined to consumption of contaminated food but should also encompass other means by which food could pose a hazard.

- Understanding people's knowledge and behaviour when assessing risks of foodborne transmission is as important as understanding virus characteristics and epidemiology. 


\section{Financial support and sponsorship}

MI-G and SJOB are supported by the NIHR Health Protection Research Unit in Gastrointestinal Infections at the University of Liverpool in partnership with Public Health England (PHE), and in collaboration with the Universities of East Anglia and Oxford and the Institute of Food Research. MIG and SJO'B are based at the University of Liverpool.

\section{Disclaimer}

The views expressed are those of the author(s) and not necessarily those of the NHS, the NIHR, the Department of Health or Public Health England. 
Figure Legend:

Figure 1: Norovirus transmission cycles

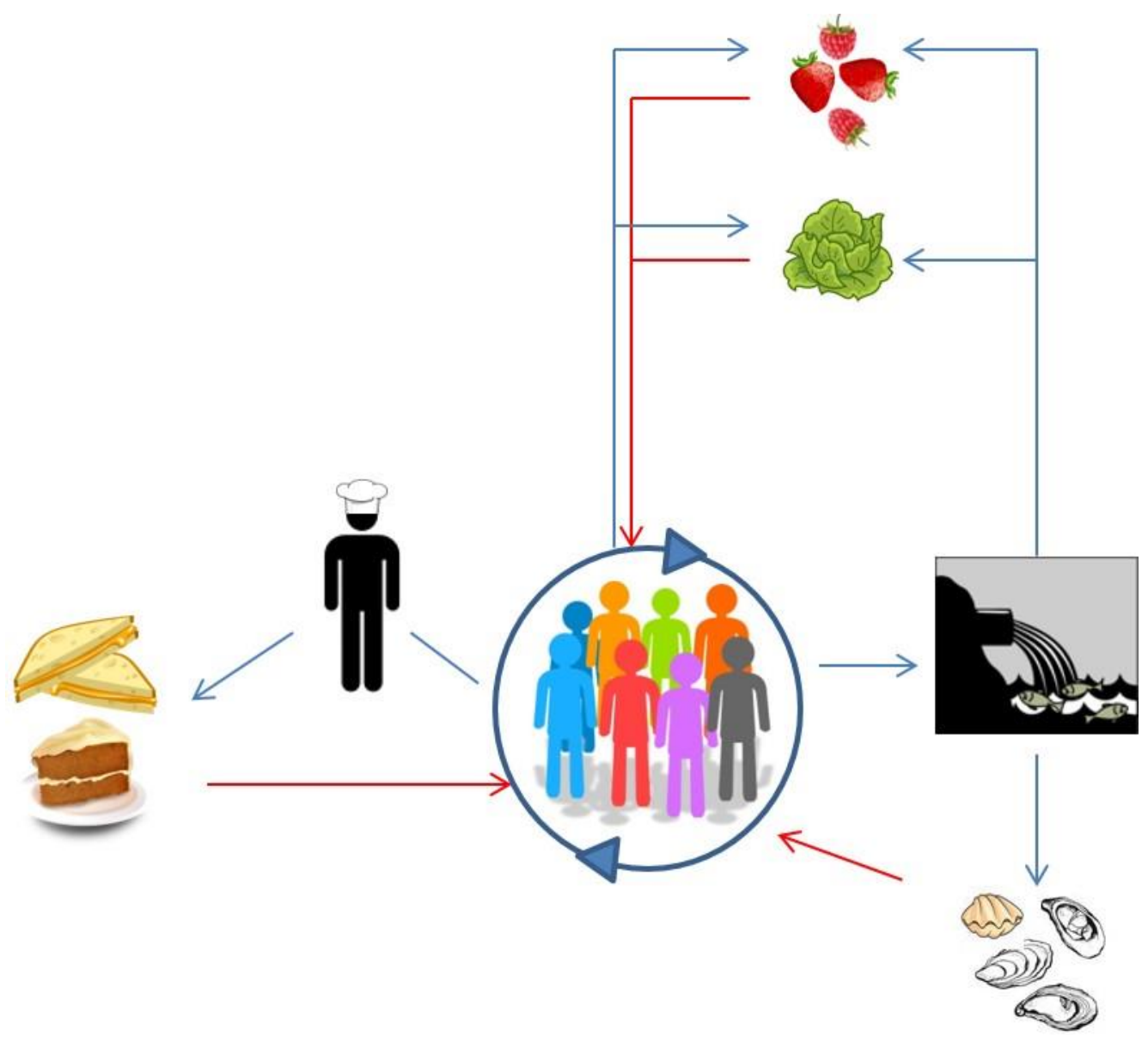




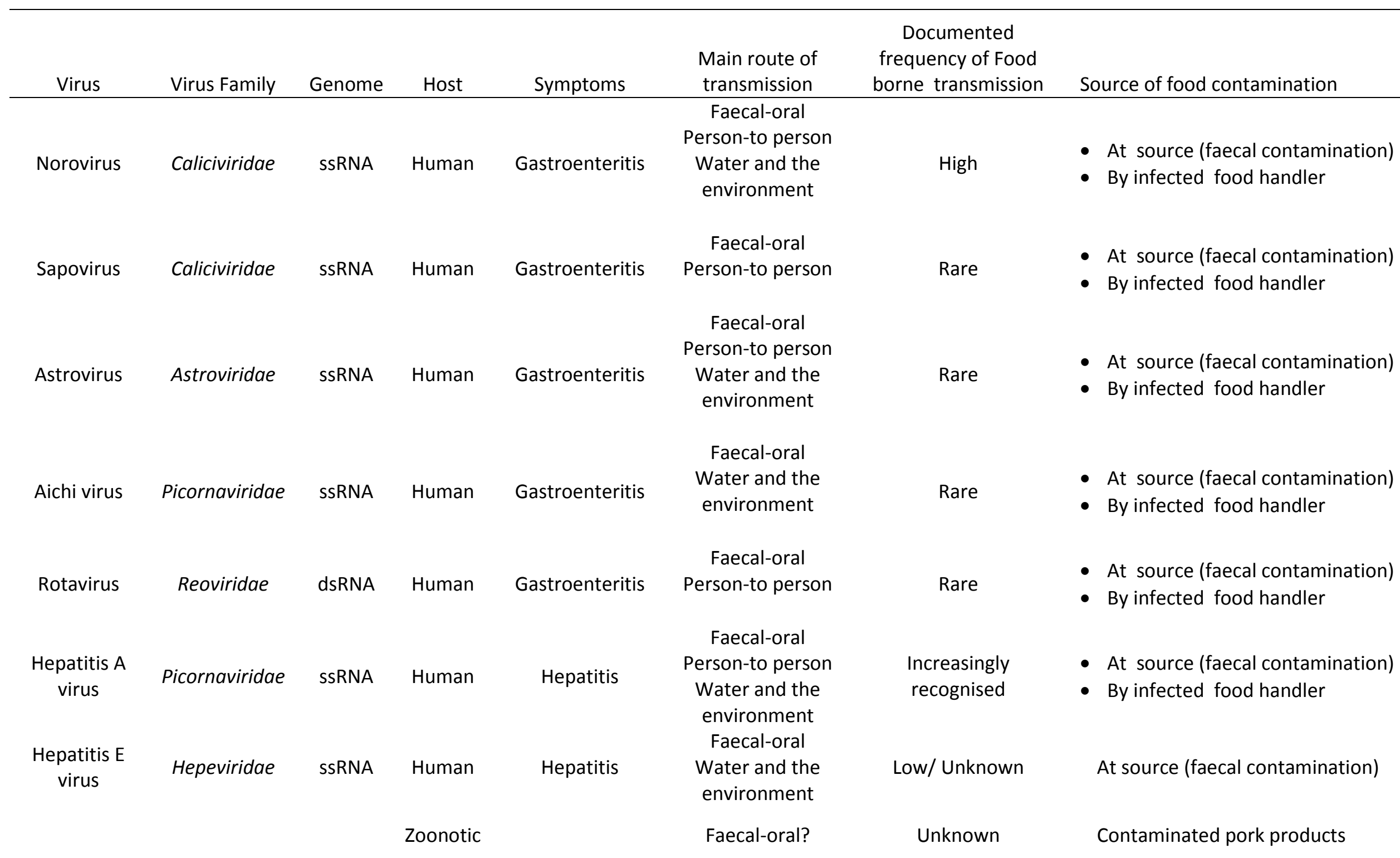





\section{References}

1. WHO. WHO estimates of the global burden of foodborne diseases. 2015. http://appswhoint/iris/bitstream/10665/199350/1/9789241565165_engpdf?ua=1

- A landmark report documenting, for the first time, the global impact of food-related illness.

2. Havelaar AH, Kirk MD, Torgerson PR, Gibb HJ, Hald T, Lake RJ, et al. World Health Organization Global Estimates and Regional Comparisons of the Burden of Foodborne Disease in 2010. PLoS medicine. 2015;12(12):e1001923. doi: 10.1371/journal.pmed.1001923. PubMed PMID: 26633896; PubMed Central PMCID: PMCPMC4668832.

- An outstanding synthesis of a very wide variety of data to develop global and regional estimates of the burden of foodborne disease covering 31 infectious and chemical hazards

3. Ajami N, Koo H, Darkoh C, Atmar RL, Okhuysen PC, Jiang ZD, et al. Characterization of norovirus-associated traveler's diarrhea. Clin Infect Dis. 2010;51(2):123-30. doi: 10.1086/653530. PubMed PMID: 20540620; PubMed Central PMCID: PMCPMC3150512.

4. Cook N, Knight A, Richards GP. Persistence and Elimination of Human Norovirus in Food and on Food Contact Surfaces: A Critical Review. Journal of food protection. 2016;79(7):1273-94. doi: 10.4315/0362-028X.JFP-15-570. PubMed PMID: 27357051.

5. He X, Wei Y, Cheng L, Zhang D, Wang Z. Molecular detection of three gastroenteritis viruses in urban surface waters in Beijing and correlation with levels of fecal indicator bacteria. Environ Monit Assess. 2012;184(9):5563-70. doi: 10.1007/s10661-011-2362-6. PubMed PMID: 21915594.

6. Kirk MD, Pires SM, Black RE, Caipo M, Crump JA, Devleesschauwer B, et al. World Health Organization Estimates of the Global and Regional Disease Burden of 22 Foodborne Bacterial, Protozoal, and Viral Diseases, 2010: A Data Synthesis. PLoS medicine. 2015;12(12):e1001921. Epub 2015/12/04. doi: 10.1371/journal.pmed.1001921. PubMed PMID: 26633831; PubMed Central PMCID: PMC4668831.

- An excellent synthesis of available data on the burden of foodborne pathogens, emphasising the importance of norovirus and hepatitis A virus.

7. Vinje J. Advances in laboratory methods for detection and typing of norovirus. Journal of clinical microbiology. 2015;53(2):373-81. Epub 2014/07/06. doi: 10.1128/JCM.01535-14. PubMed PMID: 24989606; PubMed Central PMCID: PMC4298492.

- A useful review of laboratory methods for the detection and characterisation of norovirus, which includes an up-to-date summary of the diversity and classification.

8. Verhoef L, Hewitt J, Barclay L, Ahmed SM, Lake R, Hall AJ, et al. Norovirus genotype profiles associated with foodborne transmission, 1999-2012. Emerging infectious diseases. 2015;21(4):592-9. Epub 2015/03/27. doi: 10.3201/eid2104.141073. PubMed PMID: 25811368; PubMed Central PMCID: PMC4378480.

9. Gao X, Esseili MA, Lu Z, Saif LJ, Wang Q. Recognition of Histo-Blood Group Antigen-Like Carbohydrates in Lettuce by Human GII.4 Norovirus. Applied and environmental microbiology. 2016;82(10):2966-74. Epub 2016/03/13. doi: 10.1128/AEM.04096-15. PubMed PMID: 26969699.

- An interesting study describing specific binding of norovirus to carbohydrates present in lettuce, which may contribute to the persistence and transmission of NoV by green leafy vegetables. 
10. Franck KT, Lisby M, Fonager J, Schultz AC, Bottiger B, Villif A, et al. Sources of Calicivirus contamination in foodborne outbreaks in Denmark, 2005-2011--the role of the asymptomatic food handler. J Infect Dis. 2015;211(4):563-70. doi: 10.1093/infdis/jiu479. PubMed PMID: 25156563.

- A thorough, retrospective analysis of foodborne outbreaks demonstrating that up to a quarter of foodborne calicivirus outbreaks were associated with asymptomatic infected food handlers.

11. Kobayashi S, Fujiwara N, Yasui Y, Yamashita T, Hiramatsu R, Minagawa H. A foodborne outbreak of sapovirus linked to catered box lunches in Japan. Arch Virol. 2012;157(10):1995-7. doi: 10.1007/s00705-012-1394-8. PubMed PMID: 22752792.

12. Shibata S, Sekizuka T, Kodaira A, Kuroda M, Haga K, Doan YH, et al. Complete Genome Sequence of a Novel GV.2 Sapovirus Strain, NGY-1, Detected from a Suspected Foodborne Gastroenteritis Outbreak. Genome Announc. 2015;3(1). doi: 10.1128/genomeA.01553-14. PubMed PMID: 25676762; PubMed Central PMCID: PMCPMC4333662.

-• The first published complete genome sequence of a genogroup $V$ genotype 2 sapovirus strain from a suspected foodborne gastroenteritis outbreak identified using metagenomic sequencing.

13. Matussek A, Dienus O, Djeneba O, Simpore J, Nitiema L, Nordgren J. Molecular characterization and genetic susceptibility of sapovirus in children with diarrhea in Burkina Faso. Infect Genet Evol. 2015;32:396-400. doi: 10.1016/j.meegid.2015.03.039. PubMed PMID: 25847694.

14. Pacilli M, Cortese MM, Smith S, Siston A, Samala U, Bowen MD, et al. Outbreak of Gastroenteritis in Adults Due to Rotavirus Genotype G12P[8]. Clin Infect Dis. 2015;61(4):e20-5. doi: 10.1093/cid/civ294. PubMed PMID: 25870322.

15. Mizukoshi F, Kuroda M, Tsukagoshi H, Sekizuka T, Funatogawa K, Morita Y, et al. A foodborne outbreak of gastroenteritis due to genotype G1P[8] rotavirus among adolescents in Japan. Microbiol Immunol. 2014;58(9):536-9. doi: 10.1111/1348-0421.12176. PubMed PMID: 25040046.

16. Aw TG, Wengert S, Rose JB. Metagenomic analysis of viruses associated with field-grown and retail lettuce identifies human and animal viruses. International journal of food microbiology. 2016;223:50-6. doi: 10.1016/j.ijfoodmicro.2016.02.008. PubMed PMID: 26894328.

- A very useful study demonstrating the power of metagenomics for detection of virus contamination on crops.

17. Iritani N, Kaida A, Abe N, Kubo H, Sekiguchi J, Yamamoto SP, et al. Detection and genetic characterization of human enteric viruses in oyster-associated gastroenteritis outbreaks between 2001 and 2012 in Osaka City, Japan. J Med Virol. 2014;86(12):2019-25. doi: 10.1002/jmv.23883. PubMed PMID: 24415518.

18. Thongprachum A, Khamrin P, Maneekarn N, Hayakawa S, Ushijima H. Epidemiology of gastroenteritis viruses in Japan: Prevalence, seasonality, and outbreak. J Med Virol. 2016;88(4):55170. doi: 10.1002/jmv.24387. PubMed PMID: 26387663.

19. Infections ACotMSoFAhGoFV. An update on viruses in the food chain. FSA, 2015.

20. Severi E, Verhoef L, Thornton L, Guzman-Herrador BR, Faber M, Sundqvist L, et al. Large and prolonged food-borne multistate hepatitis A outbreak in Europe associated with consumption of frozen berries, 2013 to 2014. Euro Surveill. 2015;20(29):21192. PubMed PMID: 26227370.

- The largest ever documented foodborne hepatitis A virus outbreak in Europe. 
21. Bruni R, Taffon S, Equestre M, Chionne P, Madonna E, Rizzo C, et al. Key Role of Sequencing to Trace Hepatitis A Viruses Circulating in Italy During a Large Multi-Country European Foodborne Outbreak in 2013. PLoS One. 2016;11(2):e0149642. doi: 10.1371/journal.pone.0149642. PubMed PMID: 26901877; PubMed Central PMCID: PMCPMC4764681.

22. Tavoschi L, Severi E, Niskanen T, Boelaert F, Rizzi V, Liebana E, et al. Food-borne diseases associated with frozen berries consumption: a historical perspective, European Union, 1983 to 2013. Euro Surveill. 2015;20(29):21193. PubMed PMID: 26227371.

23. Said B, ljaz S, Chand MA, Kafatos G, Tedder R, Morgan D. Hepatitis E virus in England and Wales: indigenous infection is associated with the consumption of processed pork products. Epidemiol Infect. 2014;142(7):1467-75. doi: 10.1017/S0950268813002318. PubMed PMID: 24054519.

24. Serracca L, Battistini R, Rossini I, Mignone W, Peletto S, Boin C, et al. Molecular Investigation on the Presence of Hepatitis E Virus (HEV) in Wild Game in North-Western Italy. Food and environmental virology. 2015;7(3):206-12. doi: 10.1007/s12560-015-9201-9. PubMed PMID: 26006251.

25. Lhomme S, Top S, Bertagnoli S, Dubois M, Guerin JL, Izopet J. Wildlife Reservoir for Hepatitis E Virus, Southwestern France. Emerging infectious diseases. 2015;21(7):1224-6. doi: 10.3201/eid2107.141909. PubMed PMID: 26079541; PubMed Central PMCID: PMCPMC4480389.

26. Mesquita JR, Oliveira D, Rivadulla E, Abreu-Silva J, Varela MF, Romalde JL, et al. Hepatitis E virus genotype 3 in mussels (Mytilus galloprovinciallis), Spain. Food Microbiol. 2016;58:13-5. doi: 10.1016/j.fm.2016.03.009. PubMed PMID: 27217353.

27. Grodzki M, Schaeffer J, Piquet JC, Le Saux JC, Cheve J, Ollivier J, et al. Bioaccumulation efficiency, tissue distribution, and environmental occurrence of hepatitis E virus in bivalve shellfish from France. Applied and environmental microbiology. 2014;80(14):4269-76. doi: 10.1128/AEM.00978-14. PubMed PMID: 24795382; PubMed Central PMCID: PMCPMC4068666.

28. Dupont-Rouzeyrol M, Biron A, O'Connor O, Huguon E, Descloux E. Infectious Zika viral particles in breastmilk. Lancet. 2016;387(10023):1051. doi: 10.1016/S0140-6736(16)00624-3. PubMed PMID: 26944028.

29. Hochberg NS, Bhadelia N. Infections Associated with Exotic Cuisine: The Dangers of Delicacies. Microbiol Spectr. 2015;3(5). doi: 10.1128/microbiolspec.IOL5-0010-2015. PubMed PMID: 26542047.

30. Luby SP, Rahman M, Hossain MJ, Blum LS, Husain MM, Gurley E, et al. Foodborne transmission of Nipah virus, Bangladesh. Emerging infectious diseases. 2006;12(12):1888-94. doi: 10.3201/eid1212.060732. PubMed PMID: 17326940; PubMed Central PMCID: PMCPMC3291367.

31. Rahman MA, Hossain MJ, Sultana S, Homaira N, Khan SU, Rahman M, et al. Date Palm Sap Linked to Nipah Virus Outbreak in Bangladesh, 2008. Vector-Borne Zoonot. 2012;12(1):65-72. doi: 10.1089/vbz.2011.0656. PubMed PMID: WOS:000299112800011.

32. Nahar N, Paul RC, Sultana R, Gurley ES, Garcia F, Abedin J, et al. Raw Sap Consumption Habits and Its Association with Knowledge of Nipah Virus in Two Endemic Districts in Bangladesh. PLoS One. 2015;10(11):e0142292. doi: 10.1371/journal.pone.0142292. PubMed PMID: 26551202; PubMed Central PMCID: PMCPMC4638332. 
- A very important study demonstrating the crucial importance of people's knowledge and behaviour when trying to understand exposure to, and hazards from, foodborne pathogens.

33. Melgaco FG, Victoria M, Correa AA, Ganime AC, Malta FC, Brandao ML, et al. Virus recovering from strawberries: Evaluation of a skimmed milk organic flocculation method for assessment of microbiological contamination. International journal of food microbiology. 2016;217:14-9. Epub 2015/10/20. doi: 10.1016/j.ijfoodmicro.2015.10.005. PubMed PMID: 26476572.

34. Saito H, Toho M, Tanaka T, Noda M. Development of a Practical Method to Detect Noroviruses Contamination in Composite Meals. Food and environmental virology. 2015;7(3):23948. Epub 2015/03/23. doi: 10.1007/s12560-015-9191-7. PubMed PMID: 25796206.

35. Topping JR, Schnerr H, Haines J, Scott M, Carter MJ, Willcocks MM, et al. Temperature inactivation of Feline calicivirus vaccine strain FCV F-9 in comparison with human noroviruses using an RNA exposure assay and reverse transcribed quantitative real-time polymerase chain reaction-A novel method for predicting virus infectivity. Journal of virological methods. 2009;156(1-2):89-95. Epub 2008/11/26. doi: 10.1016/j.jviromet.2008.10.024. PubMed PMID: 19028524.

36. Nowak P, Topping JR, Bellamy K, Fotheringham V, Gray JJ, Golding JP, et al. Virolysis of feline calicivirus and human GII.4 norovirus following chlorine exposure under standardized light soil disinfection conditions. Journal of food protection. 2011;74(12):2113-8. Epub 2011/12/22. doi: 10.4315/0362-028X.JFP-11-087. PubMed PMID: 22186052.

37. Nowak P, Topping JR, Fotheringham V, Gallimore Cl, Gray JJ, Iturriza-Gomara M, et al. Measurement of the virolysis of human GII.4 norovirus in response to disinfectants and sanitisers. J Virol Methods. 2011;174(1-2):7-11. doi: DOI 10.1016/j.jviromet.2011.03.004. PubMed PMID: ISI:000291521000002.

38. Afolayan OT, Webb CC, Cannon JL. Evaluation of a Porcine Gastric Mucin and RNase A Assay for the Discrimination of Infectious and Non-infectious GI.1 and GII.4 Norovirus Following Thermal, Ethanol, or Levulinic Acid Plus Sodium Dodecyl Sulfate Treatments. Food and environmental virology. 2016;8(1):70-8. Epub 2015/10/31. doi: 10.1007/s12560-015-9219-z. PubMed PMID: 26514820.

- Description of a method which may serve as a proxy for discriminating viable versus non-viable noroviruses with potential application to environmental and food surfaces.

39. Zonta W, Mauroy A, Farnir F, Thiry E. Comparative Virucidal Efficacy of Seven Disinfectants Against Murine Norovirus and Feline Calicivirus, Surrogates of Human Norovirus. Food and environmental virology. 2016;8(1):1-12. Epub 2015/10/09. doi: 10.1007/s12560-015-9216-2. PubMed PMID: 26445948.

40. Yeap JW, Kaur S, Lou F, DiCaprio E, Morgan M, Linton R, et al. Inactivation Kinetics and Mechanism of a Human Norovirus Surrogate on Stainless Steel Coupons via Chlorine Dioxide Gas. Applied and environmental microbiology. 2016;82(1):116-23. Epub 2015/10/18. doi: 10.1128/AEM.02489-15. PubMed PMID: 26475110; PubMed Central PMCID: PMC4702624.

41. Chiu S, Skura B, Petric M, McIntyre L, Gamage B, Isaac-Renton J. Efficacy of common disinfectant/cleaning agents in inactivating murine norovirus and feline calicivirus as surrogate viruses for human norovirus. American journal of infection control. 2015;43(11):1208-12. Epub 2015/08/10. doi: 10.1016/j.ajic.2015.06.021. PubMed PMID: 26254499. 
42. Knight A, Haines J, Stals A, Li D, Uyttendaele M, Jaykus LA. A systematic review of human norovirus survival reveals a greater persistence of human norovirus RT-qPCR signals compared to those of cultivable surrogate viruses. International journal of food microbiology. 2016;216:40-9. Epub 2015/09/24. doi: 10.1016/j.ijfoodmicro.2015.08.015. PubMed PMID: 26398283.

- A useful paper highlighting some of he challenges and limitations associated with the use of molecular based methods to asses norovirus infectivity or viability.

43. Jones MK, Grau KR, Costantini V, Kolawole AO, de Graaf M, Freiden P, et al. Human norovirus culture in B cells. Nature protocols. 2015;10(12):1939-47. Epub 2015/10/30. doi: 10.1038/nprot.2015.121. PubMed PMID: 26513671; PubMed Central PMCID: PMC4689599.

- A landmark paper describing the propagation of human norovirus in cell culture, providing an exciting in vitro new tool for norovirus research.

44. Baldridge MT, Nice TJ, McCune BT, Yokoyama CC, Kambal A, Wheadon M, et al. Commensal microbes and interferon-lambda determine persistence of enteric murine norovirus infection. Science. 2015;347(6219):266-9. Epub 2014/11/29. doi: 10.1126/science.1258025. PubMed PMID: 25431490; PubMed Central PMCID: PMC4409937.

-• A landmark paper identifying the important role of microbiome of norovirus persistence

45. Lee $\mathrm{H}, \mathrm{Ko} \mathrm{G}$. Antiviral effect of vitamin $\mathrm{A}$ on norovirus infection via modulation of the gut microbiome. Scientific reports. 2016;6:25835. Epub 2016/05/18. doi: 10.1038/srep25835. PubMed PMID: 27180604; PubMed Central PMCID: PMC4867650.

- Demonstration of the key role of norovirus-bacteria interaction for infection and identification of potential targets for therapeutic interventions.

46. Karst SM. Identification of a novel cellular target and a co-factor for norovirus infection - B cells \& commensal bacteria. Gut microbes. 2015;6(4):266-71. Epub 2015/05/23. doi: 10.1080/19490976.2015.1052211. PubMed PMID: 25997033; PubMed Central PMCID: PMC4615308.

- Demonstration of the key role of norovirus-bacteria interaction for infection in and in vitro culture system.

47. Li D, Breiman A, le Pendu J, Uyttendaele M. Binding to histo-blood group antigen-expressing bacteria protects human norovirus from acute heat stress. Frontiers in microbiology. 2015;6:659. Epub 2015/07/21. doi: 10.3389/fmicb.2015.00659. PubMed PMID: 26191052; PubMed Central PMCID: PMC4486850.

- Interesting paper highlighting that in addition to the role in infection norovirus binding to HBGAlike molecules may also contribute to the persistence of norovirus in the environment and in foods.

48. Tuladhar E, Hazeleger WC, Koopmans M, Zwietering MH, Duizer E, Beumer RR. Reducing viral contamination from finger pads: handwashing is more effective than alcohol-based hand disinfectants. J Hosp Infect. 2015;90(3):226-34. doi: 10.1016/j.jhin.2015.02.019. PubMed PMID: WOS:000355836400008.

- An interesting paper demonstrating poor effectiveness of alcohol sanitizers in removing norovirus form fingers. 
49. Ionidis G, Hubscher J, Jack T, Becker B, Bischoff B, Todt D, et al. Development and virucidal activity of a novel alcohol-based hand disinfectant supplemented with urea and citric acid. Bmc Infect Dis. 2016;16. doi: ARTN 7710.1186/s12879-016-1410-9. PubMed PMID: WOS:000369812900001. 